\title{
Benign bone tumors of hand and wrist: evaluation of diagnosis and treatment
}

\author{
Özgür Erdoğan, $M^{1} \mathbb{D}$, Volkan Gürkan, $M^{2}{ }^{\mathbb{D}}$ \\ 'Department of Orthopedics and Traumatology, Health Sciences University, Haydarpaşa Numune Training and Research Hospital, Istanbul, Turkey \\ ${ }^{2}$ Department of Orthopedics and Traumatology, Bezmialem Vakıf University Faculty of Medicine, Istanbul, Turkey
}

A hand or wrist bone lesion may be benign, primary malignant, or metastatic. Malignant and metastatic osseous tumors of the hand are rare, and the most common tumors are in the benign group. ${ }^{[1]}$ Benign bone tumors and tumor-like lesions of the hand and wrist are often found incidentally ${ }^{[2]}$ and reportedly account for 2-5\% of all skeletal tumors. Enchondroma was reported in up to $90 \%$ of all benign tumors of the hand. ${ }^{[1]}$ However, due to their rarity, incidences of hand and wrist benign bone tumors are still not known. ${ }^{[3]}$ Treatment generally consists of curettage and grafting, yet there remains a need for more studies investigating the choice of graft or cement. The relationship between the graft type and union rates, final range of motion (ROM), and complications is also not clear. Besides, possible reasons for recurrences, pathologic fractures, and how to prevent them are still not completely clear.

This study excluded malign lesions and only focused on benign bone tumors and tumor-like lesions of the hand and wrist. Thus, in this study, we aimed to investigate the choice of graft or cement, the relationship between the graft types and union rates, functional results, and complications in hand and wrist benign bone lesions while also evaluating the

Received: November 06, 2019

Accepted: December 11, 2019

Published online: March 02, 2020

Correspondence: Özgür Erdoğan, MD. SBÜ Haydarpaşa Numune Eğitim ve Araştırma Hastanesi Ortopedi ve Travmatoloji Kliniği, 34668 Üsküdar, İstanbul, Türkiye.

E-mail: drozgurerdogan@gmail.com

Doi: $10.5606 /$ ehc. 2020.72162

Citation: Erdoğan Ö, Gürkan V. Benign bone tumors of hand and wrist: evaluation of diagnosis and treatment. Jt Dis Relat Surg 2020;31(1):81-87.

\section{ABSTRACT}

Objectives: This study aims to investigate the choice of graft or cement, the relationship between the graft types and union rates, functional results, and complications in hand and wrist benign bone lesions while also evaluating the diagnosis and treatment modalities of lesions with high recurrence potential like giant cellcontaining lesions.

Patients and methods: Between September 2005 and May 2016, 48 benign osseous hand and wrist tumors of 48 patients ( 22 males, 26 females; mean age $33 \pm 13.1$ years; range, 11 to 70 years) were reviewed retrospectively. Patients were evaluated according to demographic data, complaints at admission, radiological findings, surgical methods, graft type, pathological diagnosis, and complications.

Results: Although not statistically significant, there were differences between cement, allograft, and autograft according to union time and loss of range of motion. There was no statistical difference between cement, allograft, and autograft according to complications.

Conclusion: Autograft obtained percutaneously with a trephine needle may provide earlier union with minimal donor site morbidity. Wide resection and reconstruction options should be kept in mind in giant cell-containing tumors. Further investigations are needed about the relationship between soft tissue edema in magnetic resonance imaging and the recurrence risk in hand and wrist benign bone tumors.

Keywords: Bone, hand, lesion, tumor, wrist.

diagnosis and treatment modalities of lesions with high recurrence potential like giant cell-containing lesions.

\section{PATIENTS AND METHODS}

This study was conducted at Bezmialem Vakıf University Faculty of Medicine between September 2005 and May 2016. STrengthening the Reporting of OBservational studies in Epidemiology (STROBE) guidelines were followed to ensure transparency. A total of 54 benign osseous hand and wrist 
tumor and tumor-like cases $(10 \%$ of all benign bone tumors) associated with the first author were retrospectively reviewed. Patients were found by using the first author's patient records. Patients with less than two years of follow-up were excluded. In order to customize the series, recurrent or revision patients previously treated at another center, low-grade chondrosarcoma $(n=4)$, and Ollier disease patients $(n=2)$ were also excluded because of different recurrence and complication rates. The remaining 48 patients ( 22 males, 26 females; mean age $33 \pm 13.1$ years; range, 11 to 70 years) were evaluated according to demographic data, complaints at the time of admission, radiological findings, surgical methods, graft type, pathological diagnosis, and

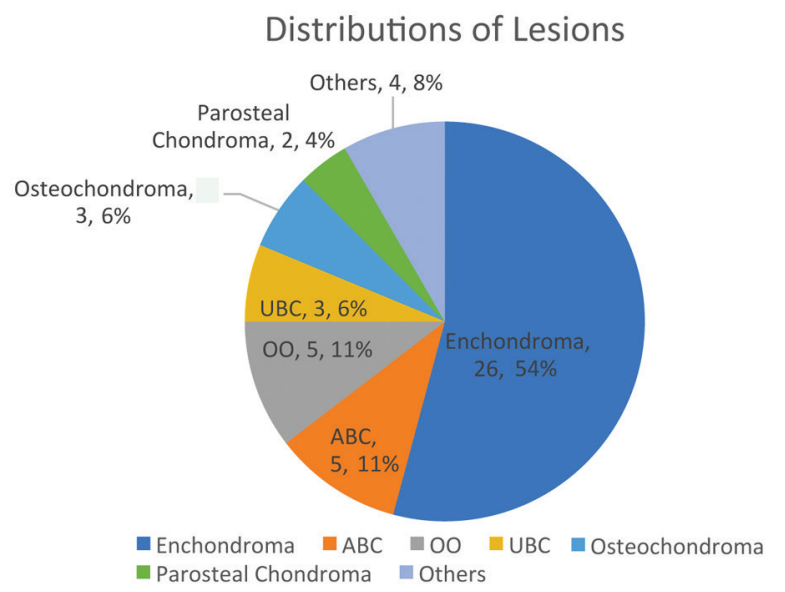

FIGURE 1. Pathologically verified distributions of lesions. ABC: Aneurysmal bone cyst; OO: Osteoid osteoma; UBC: Unicamaral bone cyst.

\section{Primary Complaint}

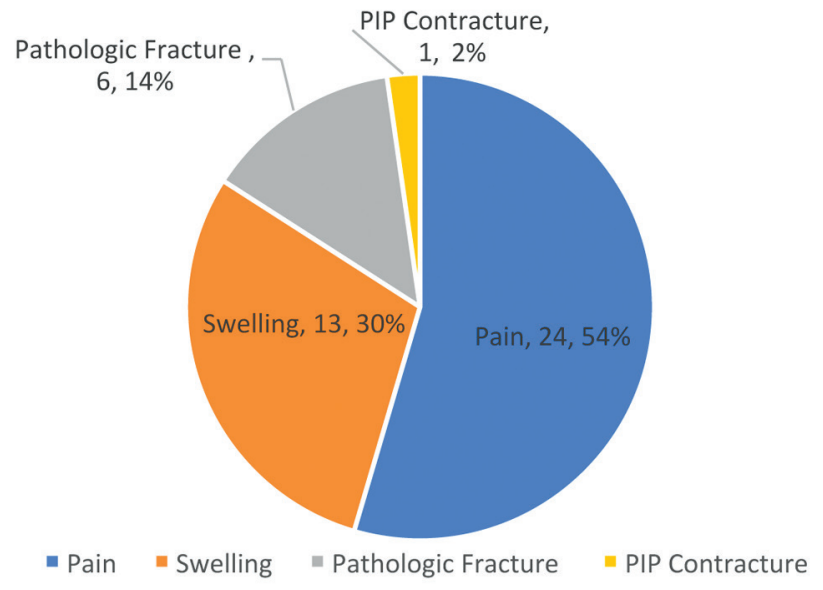

FIGURE 2. Primary complaints of patients.

PIP: Proximal interphalangeal joint. complications. Visual analog scale (VAS) and Michigan Hand Outcomes Questionnaire (MHQ) scoring systems were used for final functional evaluation. The study protocol was approved by the Bezmialem Vakıf University Faculty of Medicine Ethics Committee. A written informed consent was obtained from each patient. The study was conducted in accordance with the principles of the Declaration of Helsinki.

\section{Statistical analysis}

Statistical analysis was performed using the SPSS version 13.0 (SPSS Inc., Chigaco, IL, USA) software using an unpaired Student's t-test and the Fisher's exact test. The statistical significance level was set at $\mathrm{p} \leq 0.05$.

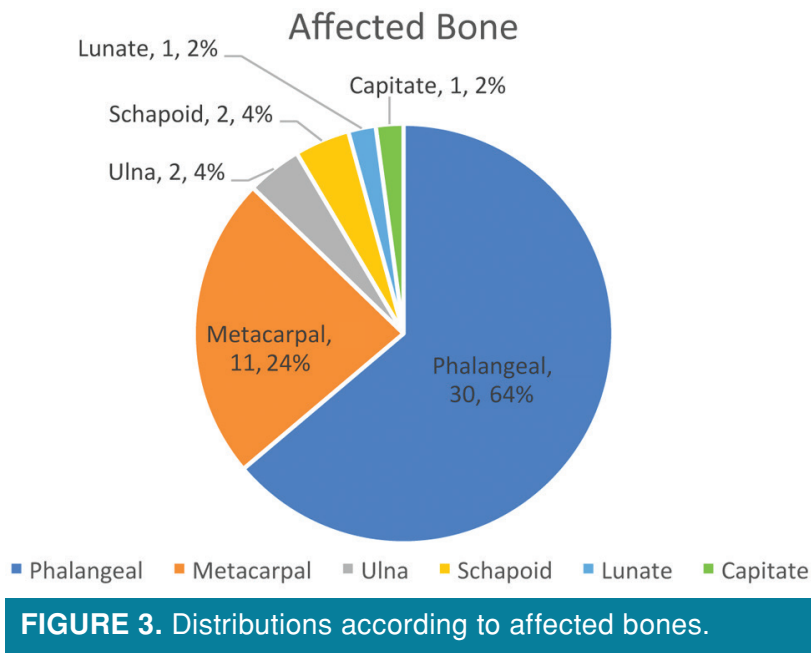

\section{Graft Type}

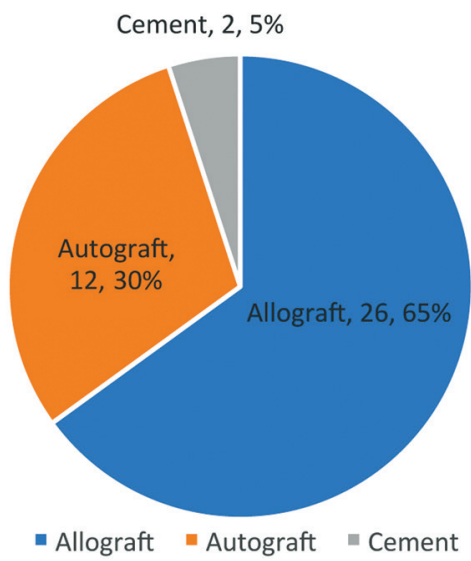

FIGURE 4. Materials used to fill defect. 


\begin{tabular}{|c|c|c|c|c|c|}
\hline Differenc & eme & raft, & $\begin{array}{c}\text { TABLE I } \\
\text { autograft accorc } \\
\text { complications }\end{array}$ & to union time, loss of rar & of motion, and \\
\hline & & & Union (weeks) & Loss of ROM (degrees) & Complications \\
\hline & $\mathrm{n}$ & $\%$ & Mean $\pm S D$ & Mean $\pm S D$ & \\
\hline Cement & 2 & 59 & None & $13.4 \pm 3.5$ & None \\
\hline Autograft & 12 & 30 & $4.7 \pm 1.4$ & $10.2 \pm 4.2$ & None \\
\hline Allograft & 26 & 65 & $5.6 \pm 1.8$ & $12.2 \pm 3.9$ & $1^{*}$ \\
\hline
\end{tabular}

\section{RESULTS}

The mean follow-up period was $79 \pm 38$ months (range, 24 to 150, median, 81 months). Pathologically verified distributions of the lesions were as follows: $26(54 \%)$ enchondromas, five $(10 \%)$ aneurysmal bone cysts (ABCs), five $(10 \%)$ osteoid osteomas, three $(6 \%)$ unicameral bone cysts, three $(6 \%)$ osteochondromas, two $(4 \%)$ parosteal chondromas, one $(2 \%)$ periosteal chondroma, one (2\%) giant cell tumor (GCT), one (2\%) epidermoid cyst, and one (2\%) giant cell reparative granuloma (GCRG)/solid component ABC (Figure 1). The primary complaints are given in Figure 2. Half of the lesions were on the right side, and the other half were on the left side. Distributions according to the affected bones are given in Figure 3. The involvements of the phalanges were as follows: distal in $14(45 \%)$, proximal in nine $(29 \%)$ and midphalangeal in eight (26\%). Forty cases $(83 \%)$ had curettage, and eight (17\%) had a marginal resection. The materials used to fill the defect are shown in Figure 4. Although not statistically significant, there were differences between cement, allograft, and autograft according to union time and lost ROM (Table I). There was no difference between cement, allograft, and autograft according to complications. Complications were one $(2 \%)$ recurrence, one $(2 \%)$ osteoid osteoma (OO), and one (2\%) superficial infection. The recurrence case was a giant cellcontaining tumor $(\mathrm{ABC})$. No donor site morbidity was observed in patients whose autograft was harvested with trephine needle. The preoperative mean VAS score was $6.1 \pm 2.9$ (range, 2 to 10, median, 5.5), and the mean MHQ score was $63.8 \pm 26.4$ (range, 26 to 96, median, 61). The mean VAS score was $8.4 \pm 0.6$ (range, 7 to 9 , median, 8.5), and the mean MHQ score was $88.3 \pm 5.4$ (range, 78 to 95 , median, 88 ) at the last follow-up.

\section{DISCUSSION}

Benign bone tumors and tumor-like lesions of the hand and wrist are rare. They are often found incidentally ${ }^{[2]}$ and reportedly account for $2-5 \%$ of all skeletal tumors. Enchondroma was reported for up to $90 \%$ of them. ${ }^{[1]}$ Treatment generally consists of curettage and grafting. We evaluated the diagnosis and treatment modalities of lesions with high recurrence potential as well as the curettage or marginal resection of giant cell lesions. Aneurysmal bone cysts have been reported as a rare condition of the hand that commonly affected patients aged less than 20 years. ${ }^{[4-6]}$ The lesion is characterized by septated blood-filled spaces, which magnetic resonance imaging (MRI) reveals as fluid-fluid levels. ${ }^{[5]}$ The tendency to affect young patients coexists with physeal injury depending on surgical treatment. Treatment with curettage and bone grafting has been reported with high recurrence rates. ${ }^{[7,8]}$ However, resection and autograft reconstruction were reported with low recurrence rates. ${ }^{[7,9]}$ In our series, $A B C$ was the second most frequent lesion and the only
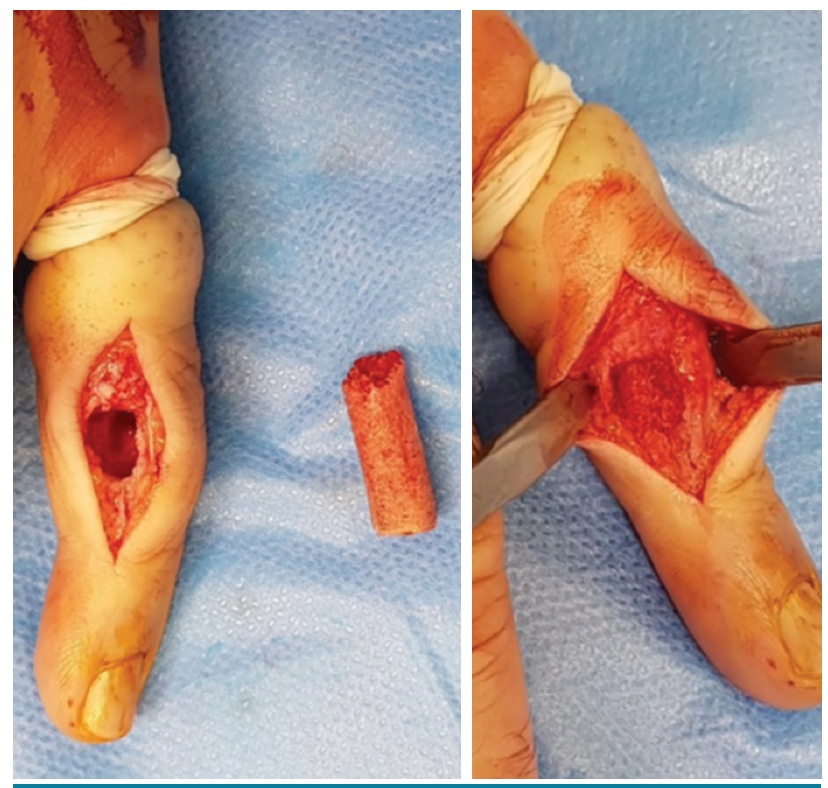

FIGURE 5. An autograft taken percutaneously by a trephine needle fits a defect accurately. 
recurrence case was an $\mathrm{ABC}$. The primary treatment was curettage with phenol, and despite this modality, a recurrence occurred and was treated successfully with en-bloc resection and autograft reconstruction. In this case, septations were only seen in X-rays. Magnetic resonance imaging showed diffuse edema in the surrounding soft tissue, and typical fluid-fluid levels were not seen. Thus, this finding may be a sign of aggression and related to recurrence. Unfortunately, to our knowledge, there is no MRI study that investigates the preoperative indicators of recurrence of an $\mathrm{ABC}$. In this patient, pathological examination showed weight of the solid components more than a typical ABC. This phenomenon could be included in the family of giant cell bone tumors, and the diagnosis may not be ABC. Severe soft tissue edema, numerous osteoclasts, mitotic activity, and atypical mitoses may hint at a possible recurrence.
We investigated the choice of graft or cement, the relationship between the graft types and union rates as well as functional results and complications. Ozaki et al. ${ }^{[10]}$ investigated 65 patients with primary ABCs. The follow-up period ranged between 24 and 161 months (median, 59.5 months). The local recurrence rate after curettage and cementation was $17 \%$, and it was $37 \%$ after curettage and bone graft. The median time between surgery and local recurrence was 17 months (range, 2 to 90 months). Although recurrence rates are significantly lower with cement in hand bones, the lesion/bone volume rate is higher than long bones, and filling a lesion with cement covering most of the bone is not preferred. Roudbari et al. ${ }^{[11]}$ investigated surgically treated benign bone tumors from 119 patients. They included information regarding age, gender, tumor type and location, staging, graft type, bone incorporation, and recurrence. Of 119 patients, 63 were treated with
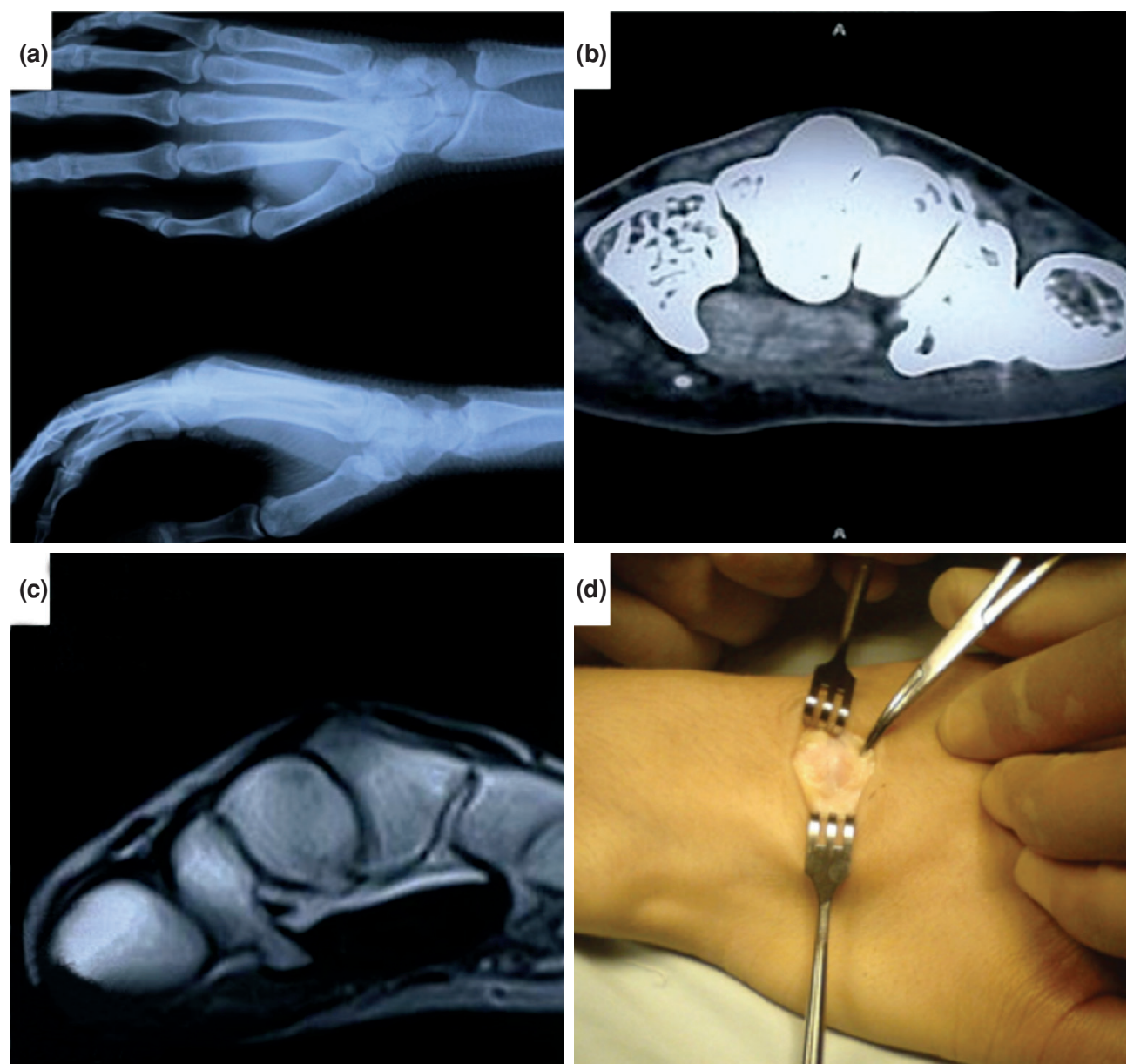

FIGURE 6. (a) X-rays show a capitate osteochondroma of a 25-year-old female patient, (b) axial computed tomography section of same patient, (c) axial magnetic resonance imaging section, (d) perioperative view. 
an allograft, and 56 were treated with an autograft. Complete graft incorporation to the bone was encountered in six months in $97 \%$ of patients. They concluded that there was no significant relationship between graft type and bone incorporation. In that study, the median time of recurrence was 20 months in the allograft group and nine months in the autograft group. Generally, allografts create a more difficult environment for tumor recurrence than autografts. ${ }^{[11]}$ In our study, although not statistically significant, loss of ROM and union time were lesser than cement with autograft. Autograft taken with a trephine needle may provide earlier union with minimal donor site morbidity. ${ }^{[12]}$ No difference was found between autograft, allograft and cement according to complications. However, this may be due to the not sufficient number of patients for comparison.

The pathologic fracture rate due to hand tumors was reported as $7 \% .^{[1]}$ In our series, this rate was found to be twice as high $(13 \%)$. Of the six pathological fracture cases, four were enchondromas, one was $\mathrm{ABC}$, and one was simple bone cyst (SBC). There was no significant delay in diagnosis or treatment, which explains the pathological fracture. The higher incidence of pathologic fractures may indicate a misdiagnosis of low-grade chondrosarcoma as an enchondroma.

Although no difference was found between graft types according to union rates, final ROM, and complications, we suggest using autograft to fill
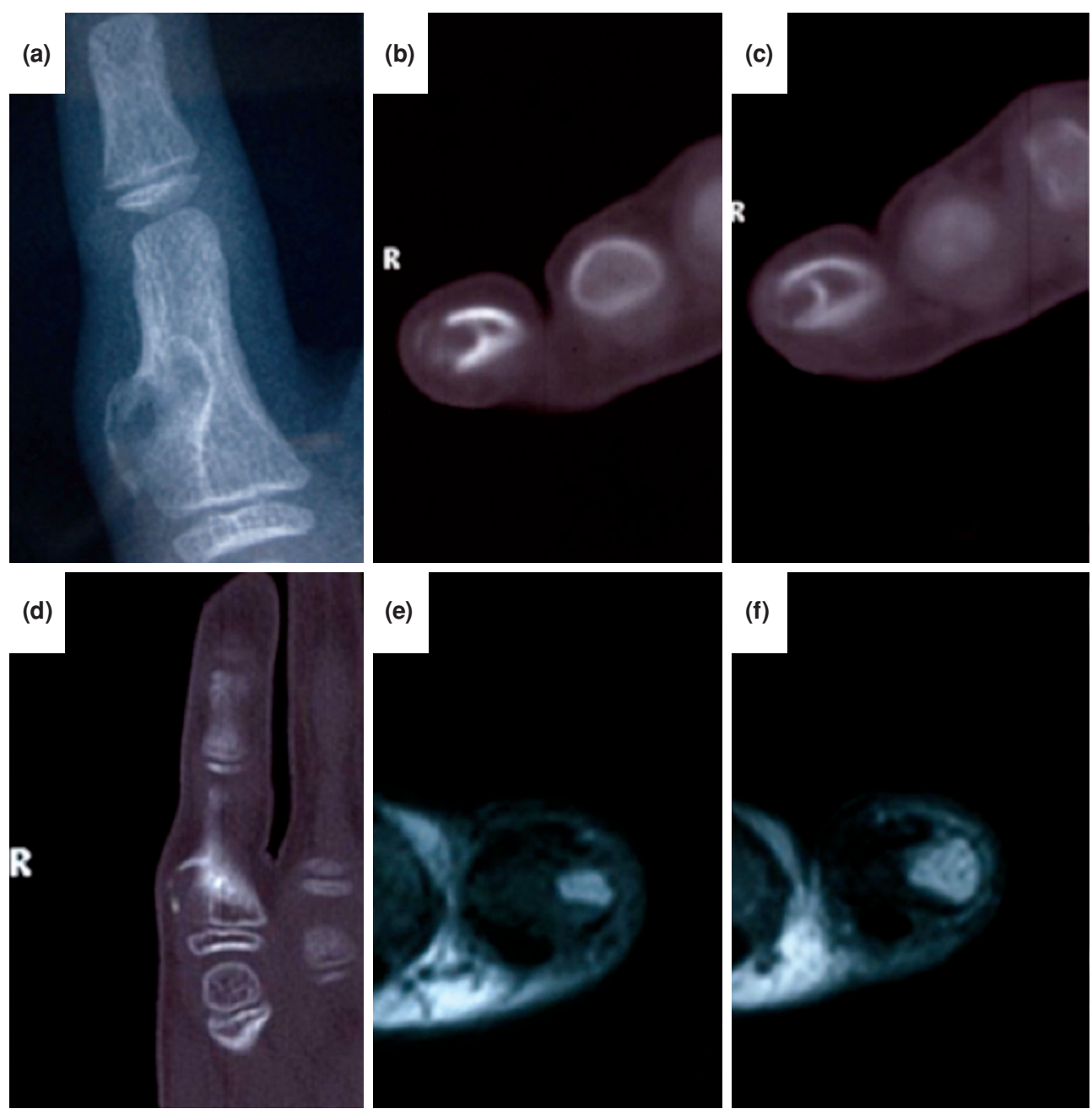

FIGURE 7. (a) X-ray shows a periosteal chondroma settled on fifth proximal phalangeal of an 11-year-old boy patient, (b, c) axial computed tomography section of same patient, (d) coronal computed tomography section, (e, f) axial magnetic resonance imaging sections. 
the defect. The graft that is taken from the iliac crest percutaneously by the trephine needle ensures complete compliance with the defect, and the donor site morbidity should be minimal (Figures 5 and 6).

Giant cell reparative granuloma or solid $A B C$ is a non-neoplastic bone mass initially described by Jaffe in $1953 .{ }^{[13]}$ Lorenzo et al. ${ }^{[14]}$ first described GCRG in hand bones. These lesions were postulated as a reactive process to trauma and showed the histological features of the $\mathrm{ABC}$ wall. ${ }^{[15]}$ Recently, a series of 26 giant cell-containing tumors were reported. Twenty-four cases were GCRGs, and only two were GCTs. ${ }^{[16]}$ Authors concluded that the GCRG ratio among giant cell lesions might be higher than expected in the hand region. Correlation of clinical, radiologic, and laboratory findings is required for accurate histopathologic diagnosis and treatment. ${ }^{[17]}$ In our series, there was only one GCRG case. The low number of GCRG maybe due to a misdiagnosis of a giant cell-containing tumor as an ABC.

Parosteal chondroma or bizarre parosteal osteochondromatous proliferation, which is also known as a Nora's lesion, was first described by Nora et al. ${ }^{[18]}$ The lesion is more prone to the hand compared to the foot. In the hand region, it usually affects phalanges and metacarpals. Unlike periosteal osteochondromas, there are no cortical changes, and unlike osteochondroma, there is no continuity within the medullary canal. ${ }^{[19]}$ Also, there is histological atypia in the chondral cap, and recurrence rates are high with excision. ${ }^{[18-20]}$ In this
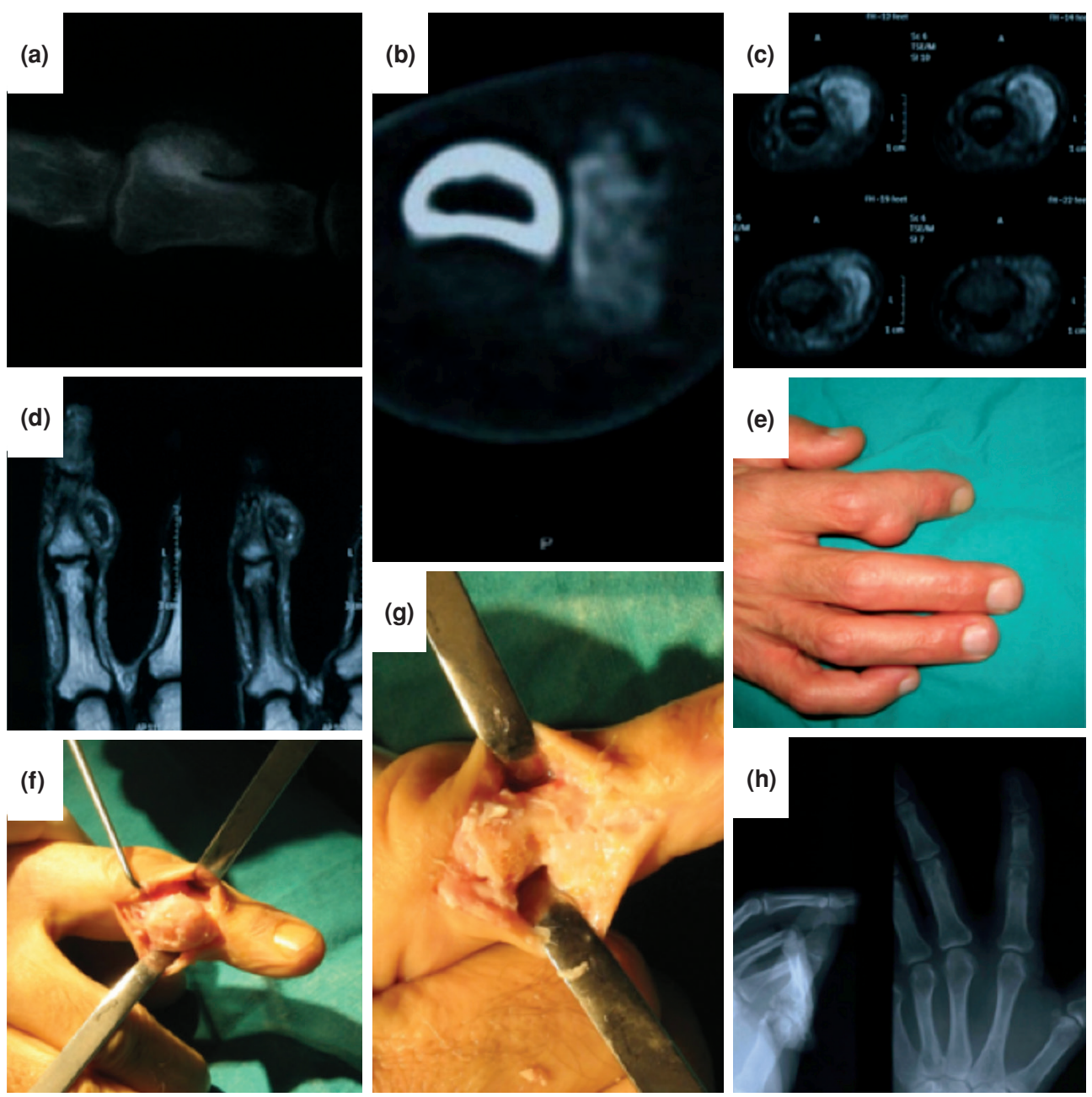

FIGURE 8. (a) X-ray shows a Nora's lesion settled on second midphalangeal of a 52-year-old male patient, (b) axial computed tomography section of same patient, (c, d) axial and coronal magnetic resonance imaging sections, (e) clinical appearance of lesion, $(\mathbf{f}, \mathbf{g})$ perioperative view, (h) postoperative X-rays. 
article, we reported two phalangeal lesions (4\%) and different from the literature with no recurrence (Figures 7 and 8).

This study has some limitations. Although the number of cases is relatively high, the number of rare types like giant cell tumor or DHRG/solid ABC is low. Also in this study complication rate was low. Larger series comparing graft and cement applications are needed.

In conclusion, autograft obtained percutaneously with a trephine needle may provide earlier union with minimal donor site morbidity. Wide resection and reconstruction options should be kept in mind in giant cell-containing tumors. Further investigations are needed about the relationship between soft tissue edema in MRI and the recurrence risk in hand and wrist benign bone tumors.

\section{Declaration of conflicting interests}

The authors declared no conflicts of interest with respect to the authorship and/or publication of this article.

\section{Funding}

The authors received no financial support for the research and/or authorship of this article.

\section{REFERENCES}

1. Payne WT, Merrell G. Benign bony and soft tissue tumors of the hand. J Hand Surg Am 2010;35:1901-10.

2. Melamud K, Drapé JL, Hayashi D, Roemer FW, Zentner J, Guermazi A. Diagnostic imaging of benign and malignant osseous tumors of the fingers. Radiographics 2014;34:1954-67.

3. Farzan M, Ahangar P, Mazoochy H, Ardakani MV. Osseous tumours of the hand: a review of 99 cases in 20 years. Arch Bone Jt Surg 2013;1:68-73.

4. Georgiannos D, Lampridis V, Bisbinas I. Phenolization and coralline hydroxyapatite grafting following meticulous curettage for the treatment of enchondroma of the hand. A case series of 82 patients with 5-year follow-up. Hand (N Y) 2015;10:111-5.

5. Lee SJ, Choo HJ, Heo YJ, SW Kim, Cho KH, Suh KJ, et al. Bone Tumors of the Hands: Focus on CT and MR Findings. Austin J Radiol 2017;4:1074.
6. Tillman BP, Dahlin DC, Lipscomb PR, Stewart JR. Aneurysmal bone cyst: an analysis of ninety-five cases. Mayo Clin Proc 1968;43:478-95.

7. Frassica FJ, Amadio PC, Wold LE, Beabout JW. Aneurysmal bone cyst: clinicopathologic features and treatment of ten cases involving the hand. J Hand Surg Am 1988;13:676-83.

8. Athanasian EA, McCormack RR. Recurrent aneurysmal bone cyst of the proximal phalanx treated with cryosurgery: a case report. J Hand Surg Am 1999;24:405-12.

9. Jafari D, Shariatzadeh H, Mazhar FN, Ghahremani MH, Jalili A. Enchondroma of the hand: the role of biopsy in the course of diagnosis and treatment. Medical Journal of Islamic Republic of Iran 2011;25:127-30.

10. Ozaki T, Hillmann A, Lindner N, Winkelmann W. Cementation of primary aneurysmal bone cysts. Clin Orthop Relat Res 1997;337:240-8.

11. Roudbari S, Haji Aliloo Sami S, Roudbari M. The clinical results of benign bone tumor treatment with allograft or autograft. Arch Iran Med 2015;18:109-13.

12. Atik OŞ. Is there something new and interesting in my article? Eklem Hastalik Cerrahisi 2019;30:69.

13. Jaffe HL. Giant-cell reparative granuloma, traumatic bone cyst, and fibrous (fibro-oseous) dysplasia of the jawbones. Oral Surg Oral Med Oral Pathol 1953;6:159-75.

14. Lorenzo JC, Dorfman HD. Giant-cell reparative granuloma of short tubular bones of the hands and feet. Am J Surg Pathol 1980;4:551-63.

15. Sanerkin NG, Mott MG, Roylance J. An unusual intraosseous lesion with fibroblastic, osteoclastic, osteoblastic, aneurysmal and fibromyxoid elements. "Solid" variant of aneurysmal bone cyst. Cancer 1983;51:2278-86.

16. MacDonald DF, Binhammer PA, Rubenstein JD, Fornasier VL. Giant cell reparative granuloma of the hand: case report and review of giant cell lesions of hands and feet. Can J Surg 2003;46:471-3.

17. Shaikh S, Lombay B. Osteoid osteoma: diagnosis and treatment. Magy Radiol 2008;82:16-24.

18. Nora FE, Dahlin DC, Beabout JW. Bizarre parosteal osteochondromatous proliferations of the hands and feet. Am J Surg Pathol 1983;7:245-50.

19. Gruber G, Giessauf C, Leithner A, Zacherl M, Clar H, Bodo K, et al. Bizarre parosteal osteochondromatous proliferation (Nora lesion): a report of 3 cases and a review of the literature. Can J Surg 2008;51:486-9.

20. Meneses MF, Unni KK, Swee RG. Bizarre parosteal osteochondromatous proliferation of bone (Nora's lesion). Am J Surg Pathol 1993;17:691-7. 